\title{
Causes and Stages of Hepatocellular Carcinoma at Patient Presentation at a Tertiary Medical Center in Western Saudi Arabia
}

\author{
Shadi Alkhayyat', Hind I. Fallatah²*, Hisham O. Akbar², Mahmoud S. Al Ahwal1, \\ Waleed S. Al Ghamdi ${ }^{2}$ \\ ${ }^{1}$ Oncology Unit, Department of Internal Medicine, King Abdul Aziz University Hospital, Jeddah, Saudi Arabia \\ ${ }^{2}$ Hepatology Unit, Department of Internal Medicine, King Abdul Aziz University Hospital, Jeddah, Saudi Arabia \\ Email: ${ }^{*}$ hindfallatah@hotmail.com
}

Received 15 September 2014; revised 10 October 2014; accepted 8 November 2014

Copyright (C) 2014 by authors and Scientific Research Publishing Inc. This work is licensed under the Creative Commons Attribution International License (CC BY). http://creativecommons.org/licenses/by/4.0/ (c) (†) Open Access

\section{Abstract}

Background: With 748,300 new cases diagnosed every year, hepatocellular carcinoma (HCC) is the $5^{\text {th }}$ and the $7^{\text {th }}$ most common cancer among males and females, respectively, and causes $7 \%$ of all cancer-related deaths. HCC represents more than $90 \%$ of primary liver cancers. Objective: The aim of the present study was to recognize the stages of HCC at presentation in patients who were diagnosed at King Abdul Aziz University Hospital (KAUH) and to identify the associated laboratory features of advance HCC. Materials and Methods: A retrospective analysis of 57 HCC patients admitted to KAUH between January 2008 and December 2012 was conducted. The diagnosis was established using ultrasound (U/S), computed tomography (CT) and/or magnetic resonance imaging (MRI), with or without a liver biopsy, as well as blood testing for alpha-fetoprotein. The following data were extracted from the medical records at KAUH: patient demographics (age, sex and nationality), laboratory results (CBC, LFT, PT, INR and alpha-fetoprotein), radiological results, biopsy results for those patients who underwent biopsy, outcomes (living, deceased or lost from the follow-up), and mortality and survival rates. Results: A total of 57 HCC patients were admitted during the study period, and 3 patients were excluded from the analysis. Of the remaining 54 patients, 44 $(81.5 \%)$ were males and $10(18.5 \%)$ were females. The mean age was 64.54 years (SD, 11.2 years; range, 31 - 86 years). The majority of patients were Saudis $(19,35.2 \%)$, non-Saudis $(35,64.8 \%)$, Egyptians $(9,16.6 \%)$ and Yemenis $(7,13 \%)$. The remaining $19(35.2 \%)$ patients comprised other nationalities. Chronic hepatitis $\mathrm{C}$ virus was the most common cause for liver cirrhosis (35 patients, $64.8 \%)$. CT was the primary diagnostic method (37 patients $68.5 \%)$, while $9(16.7 \%)$ cases were confirmed by adnominal MRI. Six patients (11.1\%) were diagnosed with abdominal ultrasound

\footnotetext{
"Corresponding author.
}

How to cite this paper: Alkhayyat, S., Fallatah, H.I., Akbar, H.O., Al Ahwal, M.S. and Al Ghamdi, W.S. (2014) Causes and Stages of Hepatocellular Carcinoma at Patient Presentation at a Tertiary Medical Center in Western Saudi Arabia. Journal of Cancer Therapy, 5, 1303-1310. http://dx.doi.org/10.4236/jct.2014.514130 
examination and elevated alpha-fetoprotein levels. In $2(3.7 \%)$ patients, HCC was confirmed by liver biopsy. The majority of the patients $(37,68.5 \%)$ had advanced disease. Only 21 (39\%) patients underwent radio frequency appellation (RFA). The mean survival time from diagnosis to death was 5.9 months (SD, 5.7 months), and the longest survival time to death was 20 months. Conclusion: The majority of our patients presented at an advanced disease stage, and CHC was the most common underlying cause for liver cirrhosis in our cohort of HCC patients. The proper implementation of HCC screening programs for cirrhotic patients is expected to help detect the treatable stages of HCC in a timely manner.

\title{
Keywords
}

\author{
Hepatocellular Carcinoma (HCC), Chronic Hepatitis B (CHB), Chronic Hepatitis C (CHC), Radio \\ Frequency Ablation (RFA), Sorafenib, Saudi Arabia
}

\section{Introduction}

Hepatocellular carcinoma (HCC) is the $5^{\text {th }}$ most common cancer among males and the $7^{\text {th }}$ most common cancer among females, with 748,300 new HCC cases diagnosed globally each year [1]. HCC is also the second most common cause of cancer-related deaths among males and the seventh among females, with 695,900 liver cancer deaths every year, particularly in areas with chronic viral hepatitis B and C [1]-[3]. Chronic hepatitis B (CHB) infection in Saudi Arabia has been highly prevalent in the past, as reflected in the previously high rates of hepatitis B virus (HBV)-associated HCC [4]-[6]. However, the implementation of effective neonatal and early childhood HBV vaccination programs for HBV has resulted in a significant decline in the prevalence of HBV among Saudi populations [4] [7] [8]. This implementation is expected to result in a significant drop in HBV-related HCC cases in Saud Arabia. Similarly, chronic hepatitis C (CHC)-related liver cirrhosis and HCC are also frequently reported in Saudi Arabia [9]-[11]. The presentation of HCC can be variable, ranging from small focal liver lesions that could be detected during routine radiological screenings of cirrhotic patients to advanced disease with severe local invasion or even distant metastasis [3] [12] [13]. Several scoring systems have been proposed for the staging of HCC [14]-[16]. Among the major international liver associations, the most widely accepted systems are the Barcelona clinic liver cancer (BCLC) criteria and the Milan criteria [14] [15]. Early HCC detection, and hence early treatment interventions, will reduce HCC-related mortality and morbidity [14]-[16]. Several studies have evaluated the possible predictive factors that are associated with advanced HCC versus less advanced HCC, for which treatment intervention can be offered [14] [15] [17] and [18]. In the present study, we retrospectively analyzed the clinical data and outcomes of HCC patients at King Abdul Aziz University Hospital Jeddah from 2008 to 2012.

\section{Methods}

\subsection{Aim}

The aim of this study was to recognize the different stages of HCC at presentation at KAUH and to identify the clinical and laboratory features associated with advanced HCC.

Design and study population: the study was conducted using a retrospective analysis. The studied population included male and female patients who had been diagnosed with HCC between January 2008 and December 2012 and were then followed-up with both hepatology and oncology care. The HCC diagnosis was established using abdominal ultrasound (U/S), computed tomography (CT) and/or magnetic resonance imaging (MRI), with or without a liver biopsy, as well as blood testing for alpha-fetoprotein.

\subsection{Exclusion Criteria}

1. Patients who had focal liver lesions, but a biopsy confirmed the presence of another hepatic neoplasm (benign or metastatic). 
2. Patients diagnosed with HCC at another hospital but completed the follow-up at KAUH.

3. HCC patients with incomplete data.

We obtained demographic data (age, sex and nationality) for each patient. We also obtained laboratory results for all patients, including complete blood count (CBC) at the time of diagnosis (white blood cells [WBC] normal 3 $11 \mathrm{~K} / \mathrm{UL}$, hemoglobin [Hg] normal 12 - $17 \mathrm{~g} / \mathrm{dl}$, platelet count [plat] normal 100 - $400 \mathrm{~K} / \mathrm{UL}$, prothrombin time $[\mathrm{PT}]$ and international normalized ratio [INR]), liver tests (aspartate amino transferase [AST] normal 15 - 37 U/L, alanine aminotransferase [ALT] normal 30 - $65 \mathrm{U} / \mathrm{L}$, alkaline phosphatase [ALP] normal 50 - $136 \mathrm{U} / \mathrm{L}$, gamma-glutamyltransferase [GGT] normal 5 - 85 U/L, AST normal 15 - $37 \mathrm{U} / \mathrm{L}$, total and direct bilirubin normal $0-17$ and $0-5 \mu \mathrm{mol} / \mathrm{L}$, respectively). We also measured the alpha fetoprotein (normal $0-5.8 \mathrm{IU} / \mathrm{ML}$ ) blood levels, and the result of the radiological measurements that confirmed the HCC diagnosis. The patients who underwent a liver biopsy to confirm HCC were reported. We categorized HCC into 4 stages, according to the BCLC classification: early stage a, intermediate stage B, advanced stage C and end stage disease D [15]. The outcome of each patient was defined as alive, documented hospital mortality or lost to follow-up. The time elapsed from the follow-to the final outcome was calculated. The length of survival for each deceased patient was also identified.

The data were analyzed using the Statistical Package for Social Sciences (SPSS, version 16), and descriptive data were collected. We used a T test to obtain the relationship between the sex and the other numeric variables. We also used multiple regression analysis to define the association between the disease stage and other variables.

\section{Result}

A total of 57 patients were diagnosed with HCC during the study period; 3 patients were excluded based on the exclusion criteria. Of the remaining 54 patients, 44 (81.5\%) were males. The mean age was 64.54 years (SD, 11.2 years; range, 31 - 86 years). Most of the patients were Saudis, followed by Egyptians and Yemenis; the remaining 19 patients comprised 11 other nationalities. Table 1 shows the demographic data for the patients included in the study. The female patients were older compared to the male patients (66\% and $64.2 \%$, respectively; $\mathrm{P}=0.12$ ), but the difference was not statistically significant.

Underlying causes of liver cirrhosis:

Chronic hepatitis C virus was the most common cause of liver cirrhosis, followed by hepatitis B virus (Table 2).

\subsection{Diagnostic Method}

CT was the primary diagnostic method used for the majority of patients (37, 68.5\%), while adnominal MRI confirmed the diagnosis in 9 (16.7\%) patients; in 6 patients (11.1\%), abdominal ultrasound examination and an elevated alpha-fetoprotein level of $>400$ confirmed the diagnosis. In 2 (3.7\%) patients, HCC was confirmed by liver biopsy.

\subsection{Stages of HCC and Associated Features}

The majority of patients $(37,68.5 \%)$ had advanced disease stages, according to the BCLC and Milan criteria [14] [15]. There was no gender difference in the disease stage $(\mathrm{P}=0.55)$. Only $21(39 \%)$ patients had an intervention using radio frequency ablation (RFA), and one patient received a liver transplant for HCC after 3 RFA sessions. Two patients were administered sorafenib for 30 months.

The laboratory data and liver function test results were similar between the HCC patients with advanced disease and the HCC patients without advanced disease, as shown in Table 3. The alpha-fetoprotein levels were $>100$ IU/ML in 30 patients (55.3\%). The Saudi patients were more likely to have advanced disease compared to the non-Saudi patients 26/19 compared to 21/35, respectively, $\mathrm{P}=0.061$. Furthermore, multiple regression analysis showed that only the plat was significantly related to the disease stage (Table 4). Diabetes mellitus was diagnosed in 35 (64.8\%) of our 54 HCC patients. The HCC patients with diabetes were more likely to be older compared to the non-diabetic patients: 66.8 years (SD 9.43 years) compared to 64.1 years (SD, 14.1 years; $\mathrm{P}=0.025$ ). The patient who underwent liver transplantation is now 6 years post LT and had recurrent CHC but not HCC. 
Table 1. Demographic data of all HC patients.

\begin{tabular}{cccc}
\hline & \multicolumn{2}{c}{ Sex } & Total males and females \\
\hline Number of patients & Male $44(81.5 \%)$ & Female $10(18.5 \%)$ & 54 \\
\hline Age (years) & 62.2 & 64 & $65.54(\mathrm{SD}, 11.1)$ \\
Saudi & 14 & 5 & $19(35.2 \%)$ \\
Egyptians & 8 & 1 & $9(16.6 \%)$ \\
Yemenis & 5 & 2 & $19(35.2 \%)$ \\
Others & 17 & 2 & $7(13 \%)$ \\
\hline
\end{tabular}

Table 2. Causes of liver disease in the HCC patients.

\begin{tabular}{ccc}
\hline Cause of liver cirrhosis & Number of patients & Percent \\
\hline HCV & 35 & 64.8 \\
HBV & 6 & 11.1 \\
AIH & 1 & 1.9 \\
NAFLD & 2 & 3.8 \\
Bilharzial liver disease & 5 & 9.3 \\
HCV + HBV & 4 & 7.4 \\
Hemochromatosis and HCV & 1 & 1.9 \\
Total & 54 & 100.00
\end{tabular}

HCV: Hepatitis C virus; HBV: Hepatitis B virus; AIH: Autoimmune hepatitis; NAFLD: None alcoholic fatty liver disease.

Table 3. Laboratory results and tumor size, according to the HCC stage.

\begin{tabular}{|c|c|c|c|c|c|}
\hline Result & The tumor stage & Number of patients & Mean & Standard deviation & P value \\
\hline \multirow{2}{*}{ HG } & Advanced & 37 & 11.6868 & 2.64550 & \multirow{2}{*}{0.362} \\
\hline & Non-advanced & 17 & 11.6588 & 2.24585 & \\
\hline \multirow{2}{*}{ WBC } & Advanced & 37 & 9.2824 & 7.49829 & \multirow{2}{*}{0.189} \\
\hline & Non-advanced & 17 & 6.6612 & 3.98015 & \\
\hline \multirow{2}{*}{ PLT } & Advanced & 37 & $1.8802 \mathrm{E} 2$ & 137.17983 & \multirow{2}{*}{0.174} \\
\hline & Non-advanced & 17 & $1.2694 \mathrm{E} 2$ & 83.41573 & \\
\hline \multirow{2}{*}{ AST } & Advanced & 37 & $1.6843 \mathrm{E} 2$ & 222.79469 & \multirow{2}{*}{0.678} \\
\hline & Non-advanced & 17 & 1.9865E2 & 319.56219 & \\
\hline \multirow{2}{*}{ ALT } & Advanced & 37 & 71.6216 & 50.92334 & \multirow{2}{*}{0.096} \\
\hline & Non-advanced & 17 & $1.0912 \mathrm{E} 2$ & 122.17400 & \\
\hline \multirow{2}{*}{ GGT } & Advanced & 37 & $2.1570 \mathrm{E} 2$ & 204.80178 & \multirow{2}{*}{0.527} \\
\hline & Non-advanced & 17 & $2.7624 \mathrm{E} 2$ & 424.52731 & \\
\hline \multirow[b]{2}{*}{ PT } & Advanced & 37 & 15.0108 & 3.58088 & \multirow{2}{*}{0.165} \\
\hline & Non-advanced & 17 & 15.1753 & 2.74637 & \\
\hline \multirow{2}{*}{ AFP } & Advanced & 37 & 6.9705E3 & 21307.11712 & \multirow{2}{*}{0.289} \\
\hline & Non-advanced & 17 & $3.50 .42 \mathrm{E} 3$ & 8830.84106 & \\
\hline \multirow{2}{*}{$\begin{array}{l}\text { Size of } \\
\text { the tumor }\end{array}$} & Advanced & 37 & 5.9109 & 2.83653 & \multirow{2}{*}{0.261} \\
\hline & Non-advanced & 17 & 4.6044 & 3.54238 & \\
\hline \multirow{2}{*}{ Bilirubin } & Advanced & 37 & 1.0883E2 & 151.16150 & \multirow{2}{*}{0.946} \\
\hline & Non-advanced & 17 & 1.1494E2 & 132.63223 & \\
\hline
\end{tabular}

WBC: White blood cells; Hg: Hemoglobin; Plat: Platelet; PT: Prothrombin time; AST: Aspartate amino transferase; ALT: Alanine aminotransferase; ALP: Alkaline phosphatase; GGT: Gamma-glutamyltransferase; AFP: alpha fetoprotein. 
Table 4. Multiple regression analysis showing the relationship between variable factors and tumor sizes.

\begin{tabular}{ccccc}
\hline \multirow{2}{*}{ Model } & \multicolumn{2}{c}{ Standardized Coefficients } & $\mathrm{t}$ & Sig. \\
\cline { 2 - 2 } (Constant) & Beta & & 0.665 \\
AST & & 0.437 & 0.129 \\
ALT & 0.407 & 1.555 & 0.731 \\
GGT & -0.086 & -0.346 & 0.680 \\
PT & -0.061 & -0.416 & 0.218 \\
Bilirubin & 0.237 & 1.255 & 0.076 \\
GENDER & -0.308 & -1.828 & 0.511 \\
AGE & 0.099 & 0.663 & 0.432 \\
AFP & -0.139 & -0.794 & 0.481 \\
PLT & -0.125 & -0.712 & 0.007 \\
\hline
\end{tabular}

\subsection{Survival}

The mean survival time from diagnosis to death was 5.9 months (SD, 5.7 months); the longest survival time until death for the none transplanted patients was 20 months.

\section{Discussion}

Our study showed that most of our HCC patients are males with advanced disease at presentation. This finding is similar to the published data on HCC from other regions in Saudi Arabia and the data from the Saudi Cancer Registry [5] [6] [9] [19]. In contrast, the data differ from more recently published international data [3] [12] [13] [17].

During the last 3 years of the study, the patients were diagnosed at earlier stages because the cirrhotic patients were followed regularly and because HCC was detected earlier [3] [17]. The reason for presentation with advanced disease might be that many patients with chronic viral hepatitis are not diagnosed earlier because they are asymptomatic, and their fist presentation is with advanced HCC [9].

In our cohort, HCV-associated cirrhosis was the most frequent cause for HCC, followed by HBV-related cirrhosis. This result is similar to the recent findings of Al Sohaibani et al. in 2011 and Al Sawat et al. in 2013 [9] [20]. However, this differs from previously reported HCC data in Saudi Arabia from 1990 to 2004, which showed that HBV-associated liver disease was the predominant cause of HCC in KSA [19] [21] [22]. This recent drop in CHB as a cause for HCC and liver disease is related to the implementation of the HBV vaccination neonatal program in the country approximately 25 years ago [7] [8]. This finding aligns with several previously reported international data [3] [12] [23].

CT or MRI was needed to confirm the diagnosis in approximately $80 \%$ of the patients, which indicates that abdominal ultrasound was inefficient in the radiological confirmation of HCC; previous data have shown similar findings [3] [24]. A poor ultrasound detection rate partially reflects the limitation of US as a highly operatordependent exam [3]. Despite the limitations of US in the radiological diagnosis of HCC, international guidelines, even the most recent ones, still recommend US to screen cirrhotic patients [3] [17] [18] [23] because the use of CT and MRI as HCC screening methods has not been validated [3] [24]. However, contrast-related complications are another factor limiting CT and MRI as screening tests [3]. Although CT and MRI demonstrate great accuracy in diagnosing HCC, liver biopsy is still needed to diagnose some patients with HCC measuring $<2 \mathrm{~cm}$ [25]. In our cohort, liver biopsy was used only in 2 patients to confirm the diagnosis.

Many of the patients who presented with advanced disease were previously undiagnosed cirrhotic patients [9]. Furthermore, no local studies have confirmed the efficiency of HCC screening in cirrhotic patients or indicated the need for such data in this field [25] [26].

In our cohort, a lower plat was the only associated factor in advance versus non-advanced HCC. Many previous reports have confirmed the association between thrombocytopenia and HCC [27]. For example, it has been suggested that thrombocytopenia in a cirrhotic patient is more commonly associated with the development of 
HCC compared to non-thrombocytopenic, cirrhotic patients [18]-[20] [27]. Furthermore, patients with thrombocytopenia are more likely to have advanced hepatocellular carcinoma [28]. Other studies have included prolonged PT and elevated bilirubin. The use of non-invasive biomarkers in the diagnosis of HCC has also been evaluated [9] [21] [22] [29].

Molecular targeted therapy was effective in prolonging the survival of HCC patients, and [3] [17] [30] sorafenib was the most extensively studied medication [30]. Sorafenib alone was effective in 2 of our advanced HCC patients which had helped to delay the disease progression to disability and death for more than 18 months. New antiangiogenic medications are currently being evaluated as monotherapy or in combination with RFA [3] [17] [30].

RFA was successful in the 20 patients who underwent procedure, and it was effective in controlling the disease progression for 6 - 18 months. The international data on the use of RFA in treating HCC are promising. With early detection, many patients are achieving a cure and excellent long-term survival rates, up to 10 years in some studies [3] [31]. We were unable to locate published data on the use of RFA in Saudi Arabia. Early detection and liver transplantation are the best long-term treatment options for HCC patients [3] [11] [17] [32]. In our cohort, the liver transplantation patient had an excellent long-term outcome.

Approximately $65 \%$ of our HCC patients had diabetes. This high rate might be related to several variables. For instance, most of the patients had CHC- and CHB-related liver cirrhosis, and the association between chronic viral hepatitis and diabetes has been frequently reported in previous studies [33]. Another explanation is the high prevalence of diabetes with increasing age in Saudi Arabia. The prevalence of diabetes has been reported to be as high as $30 \%$ in some studies, and it has been shown that diabetic HCC patients were older compared to non-diabetics [34]. A third possible reason for this phenomenon is a true association between HCC and diabetes, as shown in similar data [35]. Interestingly, the evidence had shown that this risk is lower in patients with diabetes controlled with thiazolidinedione compared to metformin [1].

A mean 6-month survival rate in our re-study indicates that approximately two-thirds of our patients had advanced disease at the time of diagnosis. Similar survival rates have been reported for advanced HCC locally and internationally [9] [36] [37]. However, some patients in our cohort had a longer survival of up to 2 - 3 years; these patients underwent screening, and their diseases were diagnosed and treated early. Similar long-term survival data in cases of early detection have been shown in several studies [38] [39], which emphasizes the importance of diagnosing CLD patients in Saudi Arabia and screening high risk groups to detect early stage HCC.

\section{Limitations of the Study}

Our study is limited by being retrospective and by its small sample size.

In conclusion, our study showed that most of our HCC patients had advanced disease at presentation, which precluded or limited the treatment options. We recommend effective surveillance programs for cirrhotic and CHB patients in Saudi Arabia to improve the outcome for HCC patients.

\section{References}

[1] Jemal, A., Bray, F., Center, M.M., Ferly, J., Ward, E. and Forman, D. (2011) Global Cancer Statistics. CA: A Cancer Journal for Clinicians, 61, 69-90. http://dx.doi.org/10.3322/caac.20107

[2] Kanavos, P. (2006) The Rising Burden of Cancer in the Developing World. Annals of Oncology, 17, viii15-viii23.

[3] European Association for the Study of the Liver European Organisation for Research and Treatment of Cancer (2012) EASL-EORTC Clinical Practice Guidelines: Management of Hepatocellular Carcinoma. Journal of Hepatology, 56, 908-943.

[4] Al-Faleh, F.Z., Al-Jeffri, M., Ramia, S., Al-Rashed, R., Arif, M., Rezeig, M., Al-Toraif, I., Baksh, M., Mishkkhas, A., Makki, O., Al-Freihi, H., Mirdad, S., Al-Juma, A, Yasin, T., Al-Swailem, A. and Ayoola, A. (1999) Seroepidemiology of Hepatitis B Infection in Saudi Children 8 Years after a Mass Hepatitis B Vaccination Programme. Journal of Infection, 38, 167-170. http://dx.doi.org/10.1016/S0163-4453(99)90245-1

[5] Koriech, O.M. and Al-Kuhaymi R. (1994) Profile of Cancer in Riyadh Armed Forces Hospital. Annals of Saudi Medicine, 14, 187-194.

[6] Al-Eid, H.S. and Garcia, A.D. (2014) Cancer Incidence Report Saudi Arabia 2009. http://www.scr.org.sa/

[7] Al-Faleh, F.Z., Al-Shehri, S., Al-Ansari, S., Al-Jeffri, M., Al-Mazrou, Y., Shaffi, A. and Abdo, A.A. (2008) Long- 
Term Protection of Hepatitis B Vaccine 18 Years after Vaccination. Journal of Infection, 57, 404-409.

[8] Al Ghamdi, S.S., Fallatah, H.I., Fetyani, D.M., Al-Mughales, J.A. and Gelaidan, A.T. (2013) Long-Term Efficacy of the Hepatitis B Vaccine in a High-Risk Group. Journal of Medical Virology, 85, 1518-1512. http://dx.doi.org/10.1002/jmv.23658

[9] Alswat, K.A., Sanai, F.M., Altuwaijri, M., Albenmousa, A., Almadi, M., Al-Hamoudi, W.K., and Abdo, A.A. (2013) Clinical Characteristics of Patients with Hepatocellular Carcinoma in a Middle Eastern Population. Hepatitis Monthly, 13, e7612. http://dx.doi.org/10.5812/hepatmon.7612

[10] Madani, T.A. (2007) Hepatitis C Virus Infections Reported in Saudi Arabia over 11 Years of Surveillance. Annals of Saudi Medicine, 27, 191-194. http://dx.doi.org/10.4103/0256-4947.51500

[11] Akbar, H.O., Al Ghamdi, A., Qattan, F., Fallatah, H.I. and Al Rumani, M. (2012) Chronic Hepatitis C in Saudiarabia: Three Years Local Experience in a University Hospital. Hepatitis Monthly, 12, e6178. http://dx.doi.org/10.5812/hepatmon.6178

[12] Trevisani, F., D’Intino, P.E., Caraceni, P., Pizzo, M., Stefanini, G.F., Mazziotti, A., Grazi, G.L., Gozzetti, G., Gasbarrini, G. and Bernardi, M. (1995) Etiologic Factors and Clinical Presentation of Hepatocellular Carcinoma. Differences between Cirrhotic and Noncirrhotic Italian Patient. Cancer, 75, 2220-2232.

http://dx.doi.org/10.1002/1097-0142(19950501)75:9<2220::AID-CNCR2820750906>3.0.CO;2-4

[13] Di Bisceglie, A.M. (2002) Epidemiology and Clinical Presentation of Hepatocellular Carcinoma. Journal of Vascular and Interventional Radiology, 13, S169-S171. http://dx.doi.org/10.1016/S1051-0443(07)61783-7

[14] Mazzaferro, V., Regalia, E., Doci, R., Andreola, S., Pulvirenti, A., Bozzetti, F., Montalto, F., Ammatuna, M., Morabito, A. and Gennari, L. (1996) Liver Transplantation for the Treatment of Small Hepatocellular Carcinomas in Patients with Cirrhosis. The New England Journal of Medicine, 334, 693-700. http://dx.doi.org/10.1056/NEJM199603143341104

[15] Llovet, J.M., Brú, C. and Bruix, J. (1999) Prognosis of Hepatocellular Carcinoma: The BCLC Staging Classification. Seminars in Liver Disease, 19, 329-338. http://dx.doi.org/10.1055/s-2007-1007122

[16] Yao, F.Y., Ferrell, L., Bass, N.M., Bacchetti, P., Ascher, N.L. and Roberts, J.P. (2002) Liver Transplantation for Hepatocellular Carcinoma: Comparison of the Proposed UCSF Criteria with the Milan Criteria and the Pittsburgh Modified TNM Criteria. Liver Transplantation, 8, 765-774. http://dx.doi.org/10.1053/jlts.2002.34892

[17] Bruix, J. and Sherman, M. (2011) Management of Hepatocellular Carcinoma: An Update. Hepatology, 53, $1020-1022$. http://dx.doi.org/10.1002/hep.24199

[18] Ioannou, G.N., Splan, M.F., Weiss, N.S., McDonald, G.B., Beretta, L. and Lee, S.P. (2007) Incidence and Predictors of Hepatocellular Carcinoma in Patients with Cirrhosis. Clinical Gastroenterology and Hepatology, 5, 938-945.

[19] Mughal, T.I. and Patel, S.B. (1996) Hepatocellular Carcinoma: A Review of 140 Cases. Annals of Saudi Medicine, 16, 53-55.

[20] Alsohaibani, F., Porter, G., Al-Ashgar, H., Walsh, M., Berry, R., Molinari, M. and Peltekian, K.M. (2011) Comparison of Cancer Care for Hepatocellular Carcinoma at Two Tertiary-Care Referral Centers from High and Low Endemic Regions for Viral Hepatitis. Journal of Gastrointestinal Cancer, 42, 228-235. http://dx.doi.org/10.1007/s12029-010-9200-x

[21] Nouh, M.S., Bashi, S.A., Laajam, M.A., Mofleh, I.A. and Al-Aska, A. (1990) Hepatitis B Virus vs Schistosomiasis and Hepatocellular Carcinoma in Saudi Arabia. East African Medical Journal, 67, 139-145.

[22] Ayoola, E.A. and Gadour, M.O. (2004) Hepatocellular Carcinoma in Saudi Arabia: Role of Hepatitis B and C Infection. Journal of Gastroenterology and Hepatology, 19, 665-669. http://dx.doi.org/10.1111/j.1440-1746.2003.03334.X

[23] Herbst, D.A. and Reddy, K.R. (2012) Risk Factors for Hepatocellular Carcinoma. Clinical Liver Disease, 1, $180-182$. http://dx.doi.org/10.1002/cld.111

[24] Tan, C.H., Low, S.C. and Thng, C.H. (2011) APASL and AASLD Consensus Guidelines on Imaging Diagnosis of Hepatocellular Carcinoma: A Review. International Journal of Hepatology, 2011, Article ID: 519783. http://dx.doi.org/10.4061/2011/519783

[25] Sersté, T., Barrau, V., Ozenne, V., Vullierme, M.P., Bedossa, P., Farges, O., Valla, D.C., Vilgrain, V., Paradis, V. and Degos, F. (2012) Accuracy and Disagreement of Computed Tomography and Magnetic Resonance Imaging for the Diagnosis of Small Hepatocellular Carcinoma and Dysplastic Nodules: Role of Biopsy. Hepatology, 55, 800-806. http://dx.doi.org/10.1002/hep.24746

[26] Abdo, A.A., Hassanain, M., AlJumah, A., AlOlayan, A., Sanai, F.M., Alsuhaibani, H.A., Abdulkareem, H., Abdallah, K., AlMuaikeel, M., Al Saghier, M., Babatin, M., Kabbani, M., Bazarbashi, S., Metrakos, P. and Bruix, J., Saudi Association for the Study of Liver Diseases and Transplantation, Saudi Oncology Society (2012) Saudi Guidelines for the Diagnosis and Management of Hepatocellular Carcinoma: Technical Review and Practice Guidelines. Annals of Saudi Medicine, 32, 174-199. 
[27] Lu, S.N., Wang, J.H., Liu, S.L., Hung, C.H., Chen, C.H., Tung, H.D., Chen, T.M., Huang, W.S., Lee, C.M., Chen, C.C. and Changchien, C.S. (2006) Thrombocytopenia as a Surrogate for Cirrhosis and a Marker for the Identification of Patients at High-Risk for Hepatocellular Carcinoma. Cancer, 107, 2212-2222.

[28] Kubo, S., Tanaka, H., Shuto, T., Takemura, S., Yamamoto, T., Uenishi, T., Tanaka, S., Ogawa, M., Sakabe, K., Yamazaki, K. and Hirohashi, K. (2004) Correlation between Low Platelet Count and Multicentricity of Hepatocellular Carcinoma in Patients with Chronic Hepatitis C. Hepatology Research, 30, 221-225. http://dx.doi.org/10.1016/j.hepres.2004.10.005

[29] Fallatah, H. (2014) Noninvasive Biomarkers of Liver Fibrosis: An Overview. Advances in Hepatology, 2014, Article ID: 357287. http://dx.doi.org/10.1155/2014/357287

[30] Cabrera, R. (2012) Systemic Targeted Therapy beyond Sorafenib. Clinical Liver Disease, 1, 212-216. http://dx.doi.org/10.1002/cld.128

[31] Shiina, S., Tateishi, R., Arano, T., Uchino, K., Enooku, K., Nakagawa, H., Asaoka, Y., Sato, T., Masuzaki, R., Kondo, Y., Goto, T., Yoshida, H., Omata, M. and Koike, K. (2012) Radiofrequency Ablation for Hepatocellular Carcinoma: 10-Year Outcome and Prognostic Factors. The American Journal of Gastroenterology, 107, 569-577. http://dx.doi.org/10.1038/ajg.2011.425

[32] Duvoux, C., Roudot-Thoraval, F., Decaens, T., Pessione, F., Badran, H., Piardi, T., Francoz, C., Compagnon, P., Vanlemmens, C., Dumortier, J., Dharancy, S., Gugenheim, J., Bernard, P.H., Adam, R., Radenne, S., Muscari, F., Conti, F., Hardwigsen, J., Pageaux, G.P., Chazouillères, O., Salame, E., Hilleret, M.N., Lebray, P., Abergel, A., Debette-Gratien, M., Kluger, M.D., Mallat, A., Azoulay, D. and Cherqui, D., Liver Transplantation French Study Group (2012) Liver Transplantation for Hepatocellular Carcinoma: A Model Including $\alpha$-Fetoprotein Improves the Performance of Milan criteria. Gastroenterology, 143, 986-994. http://dx.doi.org/10.1053/j.gastro.2012.05.052

[33] Papatheodoridis, G.V., Chrysanthos, N., Savvas, S., Sevastianos, V., Kafiri, G., Petraki, K. and Manesis, E.K. (2006) Diabetes Mellitus in Chronic Hepatitis B and C: Prevalence and Potential Association with the Extent of Liver Fibrosis. Journal of Viral Hepatitis, 13, 303-310. http://dx.doi.org/10.1111/j.1365-2893.2005.00677.x

[34] Al-Nozha, M.M., Al-Maatouq, M.A., Al-Mazrou, Y.Y., Al-Harthi, S.S., Arafah, M.R., Khalil, M.Z., Khan, N.B., AlKhadra, A., Al-Marzouki, K., Nouh, M.S., Abdullah, M., Attas, O., Al-Shahid, M.S. and Al-Mobeireek, A. (2004) Diabetes Mellitus in Saudi Arabia. Saudi Medical Journal, 25, 1603-1610.

[35] Abbas, Z., Siddiqui, A.U., Luck, N.H., Hassan, M., Mirza, R., Naqvi, A. and Rizvi, A.H. (2008) Prognostic Factors of Survival in Patients with Non-Resectable Hepatocellular Carcinoma: Hepatitis C versus Miscellaneous Etiology. Journal of Pakistan Medical Association, 58, 602-607.

[36] Yaghi, C., Sharara, A.I., Rassam, P., Moucari, R., Honein, K., BouJaoude, J., Slim, R., Noun, R., Abdul-Baki, H., Khalifeh, M., Ramia, S. and Sayegh, R. (2006) Hepatocellular Carcinoma in Lebanon: Etiology and Prognostic Factors Associated with Short-Term Survival. World Journal of Gastroenterology, 12, 3575-3580.

[37] Paranaguá-Vezozzo, D.C., Ono, S.K., Alvarado-Mora, M.V., Farias, A.Q., Cunha-Silva, M., França, J.I., Alves, V.A., Sherman, M. and Carrilho, F.J. (2014) Epidemiology of HCC in Brazil: Incidence and Risk Factors in a Ten-Year Cohort. Annals of Hepatology, 13, 386-393.

[38] Tateishi, R., Okanoue, T., Fujiwara, N., Okita, K., Kiyosawa, K., Omata, M., Kumada, H., Hayashi, N. and Koike, K. (2014) Clinical Characteristics, Treatment, and Prognosis of Non-B, Non-C Hepatocellular Carcinoma: A Large Retrospective Multicenter Cohort Study. Journal of Gastroenterology. (Published Online). http://download.springer.com/static/pdf/32/art\%253A10.1007\%252Fs00535-014-0973-8.pdf?auth66=1413305494_df9 385b19aa7645df3d09fef19f61057\&ext=.pdf

[39] Utsunomiya, T., Shimada. M., Kudo, M., Ichida, T., Matsui, O., Izumi, N., Matsuyama, Y., Sakamoto, M., Nakashima, O., Ku, Y., Kokudo, N. and Makuuchi, M., Liver Cancer Study Group of Japan (2014) Nationwide Study of 4741 Patients with Non-B Non-C Hepatocellular Carcinoma with Special Reference to the Therapeutic Impact. Annals of Surgery, 259, 336-345. http://dx.doi.org/10.1097/SLA.0b013e31829291e9 
Scientific Research Publishing (SCIRP) is one of the largest Open Access journal publishers. It is currently publishing more than 200 open access, online, peer-reviewed journals covering a wide range of academic disciplines. SCIRP serves the worldwide academic communities and contributes to the progress and application of science with its publication.

Other selected journals from SCIRP are listed as below. Submit your manuscript to us via either submit@scirp.org or Online Submission Portal.
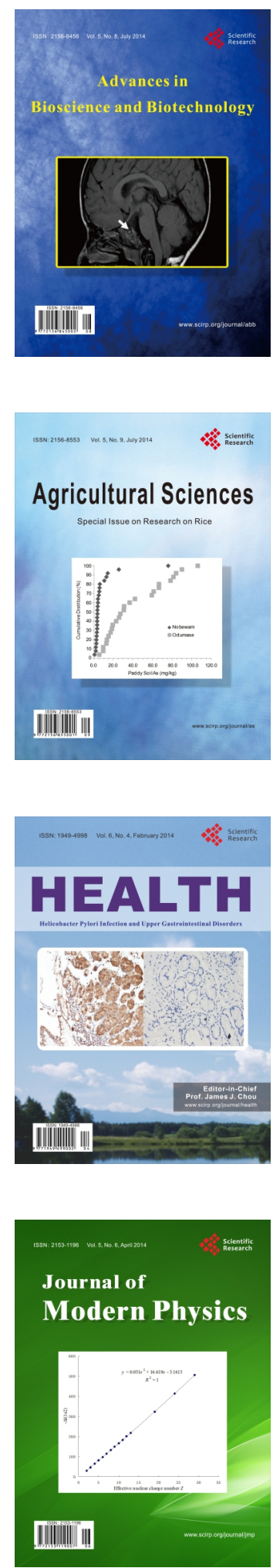
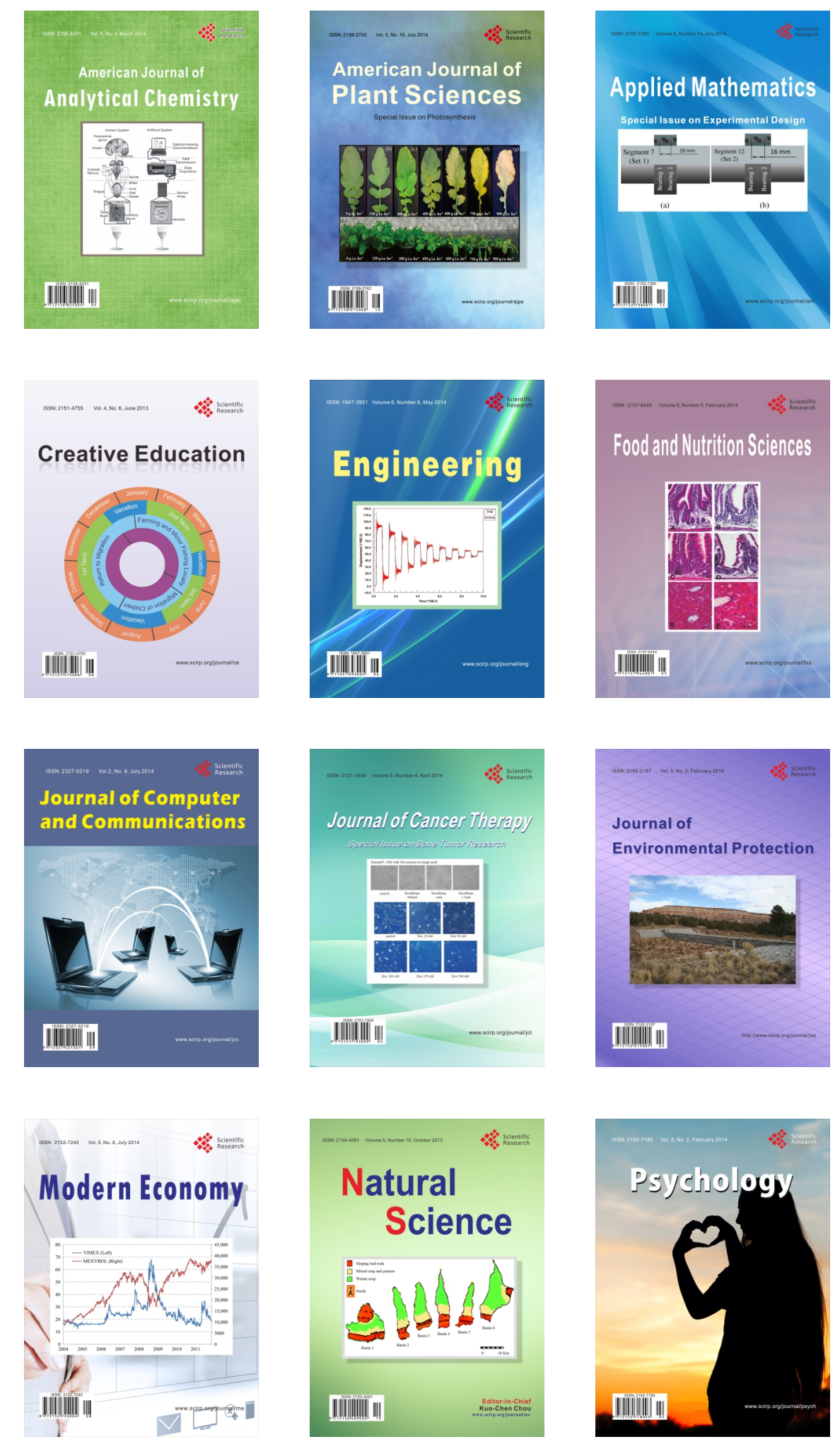